\title{
“TRÁFICO” DE MATERIAL ARQUEOLÓGICO, TURISMO E COMUNIDADES RIBEIRINHAS: EXPERIÊNCIAS DE UMA ARQUEOLOGIA PARTICIPATIVA EM PARINTINS, AMAZONAS
}

\author{
"Traffic" of Archaeological Materials, Tourism and Riverine Communities: Participatory \\ Archaeology Experiences in Parintins, Amazonas State, Brazil
}

\section{Helena Pinto Lima ${ }^{1}$ Bruno Marcos Moraes ${ }^{2}$ Maria Tereza Vieira Parente ${ }^{3}$}

\section{RESUMO}

O presente artigo formaliza uma discussão iniciada durante o I SEMINÁRIO INTERNACIONAL DE GESTÃO DO PATRIMÔNIO ARQUEOLÓGICO PANAMAZÔNICO, levado a cabo na cidade de Manaus/AM, novembro de 2007. Nessa importante ocasião foram discutidos e delineados os parâmetros para a gestão do patrimônio arqueológico amazônico. O tema deste artigo foi tratado na mesa "tráfico de material arqueológico". Apresentaremos um projeto de pesquisa desenvolvido em parceria com a Superintendência Estadual do Instituto do Patrimônio Histórico e Artístico Nacional (IPHAN) no Amazonas, que se mostrou uma experiência bem sucedida, e que pode ser utilizada para se (re)pensar as dezenas de situações semelhantes que ocorrem no interior da Amazônia e quiçá, em outras localidades do país.

Palavras chave: Tráfico de bens arqueológicos, Turismo, Arqueologia Participativa.

\section{ABSTRACT}

This paper formalizes a discussion started during the I INTERNATIONAL SEMINAR ON MANAGEMENT OF ARCHAEOLOGICAL HERITAGE PAN-AMAZON, carried out in the city of Manaus, Amazonas, in November 2007. On this important occasion were discussed and outlined the parameters for the management of the archaeological heritage of the Amazon. The theme of this article was treated on the table "trafficking in archaeological material". We will present a research project developed in partnership with the State Superintendent of the Institute of Historical and Artistic Heritage (IPHAN) in Amazonas, which proved a successful experiment, which can be used to (re)consider the dozens of similar situations occurring in the Amazon region and perhaps in other parts of the country.

Keywords: Trafficking of archaeological, Tourism, Archaeology Participatory.

\section{RESUMEN}

\footnotetext{
1 Museu Paraense Emílio Goeldi Av. Perimetral 1901, Terra Firme Belém/PA. Cep: 66070-530 helenalima@museu-goeldi.br

$\frac{2}{2}$ PPG-Ciências do Ambiente e Sustentabilidade na Amazônica/Universidade Federal do Amazonas bmoraes@insituarqueologia.com

3 Programa de Pós-Graduação em Arqueologia do Museu de Arqueologia e Etnologia da Universidade de São Paulo (mestrado inconcluso) terezaparente@gmail.com
} 
En este trabajo se formaliza una discusión iniciada durante el I Seminario Internacional de Gestión del Patrimonio Arqueológico PAN AMAZÓNICO, llevado a cabo en la ciudad de Manaus /AM, noviembre de 2007. En esta importante ocasión se discutieron y expusieron los parámetros para la gestión del patrimonio arqueológico del Amazonas. El tema de este artículo se trató en la mesa "tráfico de material arqueológico". En este artículo se presenta un proyecto de investigación desarrollado en colaboración con la Superintendencia Estatal del Instituto del Patrimonio Histórico y Artístico Nacional (IPHAN) en Amazonas, que resultó ser una experiencia exitosa, y que puede ser utilizado para (re)pensar en las muchas de situaciones similares que se producen en el Amazonas y tal vez en otras partes del país.

Palabras clave: Tráfico de arqueológico, Turismo, Arqueología Participativa.

\section{Introdução: o Projeto Baixo Amazonas}

Este artigo visa apresentar as ações, resultados e reflexões oriundas das pesquisas arqueológicas empreendidas entre os anos de 2004 e 2008 no município de Parintins/AM, sob a égide do Projeto Baixo Amazonas. A região representa um campo reconhecidamente fértil para estudos arqueológicos ao suscitar questões científicas de relevância para o entendimento da ocupação humana na Amazônia, bem como para a construção de uma história - e préhistória - em âmbito local e regional. Além disso, trabalhos educativos desenvolvidos junto às pesquisas arqueológicas em muito têm contribuído para uma reconfiguração dos debates e ações a esse respeito.

Sabe-se que vários foram os grupos indígenas que habitaram a região, e o resultado dessas ocupações é visível através da presença de inúmeros sítios arqueológicos encontrados por todo o município, a maioria deles localizados na zona rural, sob as comunidades que hoje os habitam. O próprio nome que leva o município de Parintins se dá em função de um dos grupos indígenas que ocupou a área, os Parintins ou Parintintins (SANT'ANNA NERY, 1899:229).

Parintins ocupa uma região estratégica em termos de comunicação e recursos. Observada de uma perspectiva geográfica macro-regional, ali há a confluência de uma série de rios de importância regional de médio e grande porte, tal como o Trombetas, Nhamundá, Paraná do Ramos e o Andirá. Trata-se de uma intrincada rede aquática de rios, lagos e furos, que intercomunicam os corpos d'água mais robustos. Situada à ilha de Tupinambarana, na margem direita do rio Amazonas, e ocupando um planalto escarpado, a cidade de Parintins é sede do município mais a leste do atual Estado do Amazonas, fazendo divisa com o estado do Pará (figura 1). Outra menção importante é a toponímia da ilha, local onde Pedro Teixeira deparou-se com grupos Tupinambás, em meados do séc. XVII (UGARTE 2010). 

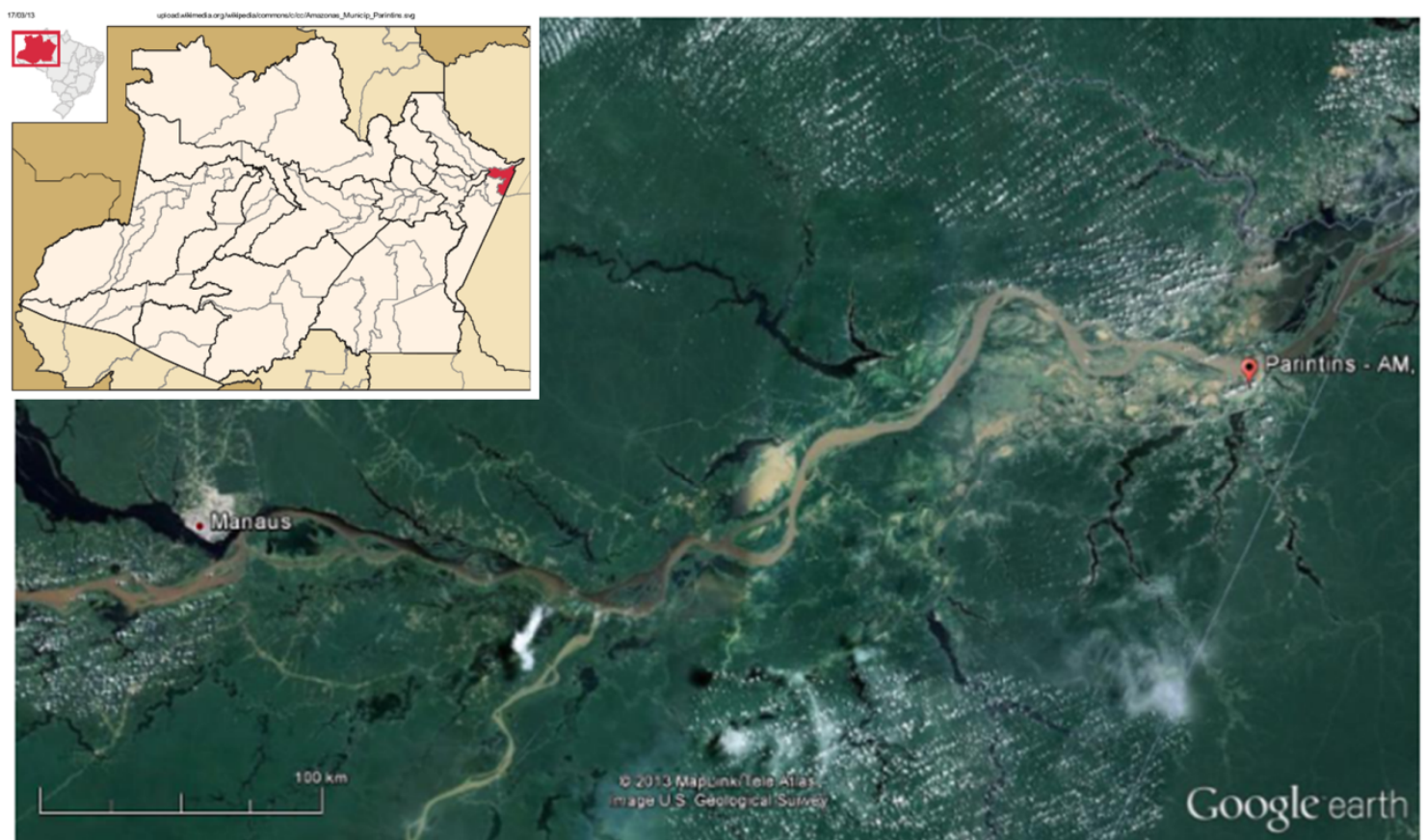

Google earth
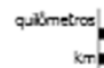

100

Fig.1: Mapa de localização do município de Parintins, Amazonas.

Nas últimas décadas, o reconhecimento nacional e internacional da riqueza natural, cultural e arqueológica do município de Parintins tem levado a um forte crescimento do turismo na região. No entanto, este rápido e desordenado crescimento, aliado ao considerável hiato existente entre a legislação brasileira quanto ao patrimônio arqueológico e a sociedade, levou Parintins a se tornar foco de preocupação com a evasão de peças arqueológicas, o que tem gerado sérias preocupações quanto a esse patrimônio.

O Projeto Baixo Amazonas surgiu como uma iniciativa conjunta entre IPHAN Instituto do Patrimônio Histórico e Artístico Nacional e PAC - Projeto Amazônia Central (MAE-USP), tendo inicialmente o objetivo geral de empreender levantamentos arqueológicos com vistas à localização, georeferenciamento e cadastramento de sítios e coleções arqueológicas em doze municípios do médio e baixo Amazonas ${ }^{4}$, no Estado do Amazonas. Estes trabalhos resultaram em uma avaliação dos sítios arqueológicos e do potencial científico das áreas visitadas, apontando sugestões e medidas a serem tomadas pelo IPHAN em curto,

\footnotetext{
${ }^{4} \mathrm{O}$ trabalho teve um caráter de diagnóstico preliminar nos municípios de Nhamundá, Parintins, Barreirinha, Boa Vista do Ramos, Maués, Urucará, Urucurituba, São Sebastião do Uatumã, Itapiranga, Silves, Itacoatiara e Manaus.
} 
médio e longo prazo (LIMA e SILVA, 2005). No município de Parintins foram identificados cinco sítios arqueológicos, descritos no mesmo texto (idem, p. 26-38).

Em função de frequentes denúncias encaminhadas ao IPHAN que colocavam a comercialização de peças arqueológicas como maior causa de sua crescente evasão, o PBA intensificou as ações em Parintins para melhor entender e lidar com essa situação. Para isso, inicialmente, empreendemos um levantamento arqueológico na área do município e procuramos fomentar o interesse local acerca da arqueologia e das questões patrimoniais a ela associadas, dialogando com diversas clivagens da população local (professores, alunos, trabalhadores rurais, comunidade acadêmica etc). Como continuidade do mesmo Projeto Baixo Amazonas, as ações arqueológicas em Parintins se concentraram no sítio Santa Rita (AM-PT-01), que foi intensamente pesquisado entre os anos de 2007 e 2008 através de uma etapa de delimitação e escavação.

Simultaneamente, foi elaborado e executado um programa de Educação Patrimonial cujas ações centraram-se na rede de comunidades associada à sede Santa Rita. Seu objetivo principal foi promover a preservação do patrimônio arqueológico e dos processos socioculturais de produção da diversidade no presente. Assim, trabalharemos com dois eixos principais: (a) o das usuais preocupações com a garantia de que as potenciais histórias e diversidades condensadas nos estratos arqueológicos sejam interpretadas cientificamente e de que sua divulgação seja efetiva e (b) o dos conhecimentos e práticas locais que embasam outras teorias e orientam outras posturas frente ao registro arqueológico, utilizando como via de acesso as relações que os moradores das comunidades estabelecem entre si e com seu ambiente natural e cultural a partir dos artefatos arqueológicos.

Vale ressaltar que a incorporação da problemática da educação às pesquisas em arqueologia encontra espaço privilegiado no centro do atual contexto de valorização da diversidade. Afinal é através dela que diferentes estratégias vêm sendo elaboradas para reverter os graus de destruição dos sítios arqueológicos e promover a valorização da diversidade sociocultural, bem como fortalecer laços de cidadania e relações de pertencimento. É certo que tal movimento vem se desdobrando através de processos que dialogam - e por vezes se sobrepõem - como por conta de movimentos próprios à disciplina (arqueologia pública), por insumos promovidos pela legislação (educação patrimonial) ou, até mesmo, por seu diálogo com outros campos do saber (musealização da arqueologia) e do mercado (turismo, desenvolvimento local, licenciamento ambiental etc.). Nesse sentido, como apontado por Carneiro, o tema da "arqueologia pública" no Brasil geralmente mescla distintos "referenciais teóricos e metodológicos, uma vez que o movimento de aproximação do 
patrimônio arqueológico junto à sociedade iniciou-se no âmbito de outros campos do conhecimento, como a museologia e a educação patrimonial" (Carneiro, 2008) - quadro que tem avançado com a publicação de diversos trabalhos acadêmicos ${ }^{5}$.

Já no que se refere à educação patrimonial, se há algum tempo tratava-se fundamentalmente de ações realizadas no âmbito dos museus e mais restritas aos sítios e monumentos do período colonial (SCHAANS, 2007), nos últimos tempos, temos assistido a um crescimento de experiências educacionais que partem da diversidade de fontes patrimoniais para estimular públicos a se apropriarem de referências históricas como forma de valorização de sua herança cultural ${ }^{6}$.

A esse respeito, como observado por Bruno, é importante destacar "que a legislação ambiental, em franco desenvolvimento nos últimos anos, contribuiu de forma expressiva para a valorização da pesquisa arqueológica, impulsionando, inclusive, o desdobramento da legislação patrimonial, com vistas ao fortalecimento da ação educativa e do tratamento curatorial dos acervos" (BRUNO, 2005: 239). Em termos mais concretos, é preciso lembrar que o principal marco legislativo que impulsionou o deslocamento e o crescimento em questão foi a Portaria $n^{\circ} 230$ do Instituto do Patrimônio Histórico e Artístico Nacional (IPHAN, 2002) que trata da divulgação do conhecimento científico produzido e da implementação de atividades de educação patrimonial no contexto de processos de licenciamento ambiental (CADARELLI, 2007; SCHAAN, 2007; LIMA, 2007; MENESES, 2007; BRUNO, 2005).

\section{A Área de Estudo: a Comunidade Santa Rita e a Região da Valéria}

A Comunidade de Santa Rita de Cássia está situada na margem direita do rio Amazonas, na região localmente conhecida como Serra da Valéria, a cerca de $50 \mathrm{~km}$ a leste da sede do município de Parintins. Constitui-se como a maior comunidade da região, que engloba ainda outras comunidades menores, ou "colônias", como Samaria, Bete Semes, São Paulo e Betel (Figura 2). É a única comunidade que permite acesso por via terrestre a partir da Balsa Vila Amazônia-Parintins, numa estrada com 59km de extensão. Por esta razão, Santa

\footnotetext{
${ }^{5}$ Publicações de artigos na Revista Arqueologia Pública (UNICAMP), Revista do MAE, Revista do Emílio Goeldi, e as produções acadêmicas de Márcia Bezerra de Almeida, (2003), Tatiana Costa Fernandes (2008) e Carla Gibertoni Carneiro são alguns exemplos de como as produções que dizem respeito às relações entre arqueologia e educação encontram-se em franco crescimento.

${ }^{6}$ Os debates acerca da pertinência em desenvolver ações voltadas para o uso do "patrimônio como fonte primária de conhecimento" (Horta et al. 1999), com vistas à preservação dos 'bens culturais’ foram trazidas para o Brasil da Inglaterra em meados da década de 1980.
} 
Rita tornou-se um polo local, sendo a maior comunidade e a que concentra bens e serviços municipais, como é o caso da escola municipal Marcelino Henrique, que aglutina estudantes de todas as outras comunidades, e do antigo posto de saúde, hoje desativado.

Santa Rita possui setenta e cinco famílias que habitam casas de madeira, em sua maioria, e alvenaria. Ruas, becos, caminhos e espaços públicos compõem a trafegabilidade no local, que possui, além da escola de ensino infantil, fundamental e médio tecnológico, água encanada, energia elétrica, dois postos de atendimento do INCRA, um em saúde e outro para trabalhos diversos, desativados desde as suas instalações. Tem-se ainda a Sede Social, Igreja, Campo de Futebol, Cemitério e telefone comunitário (COSTA, 2010: 47).

A Comunidade reúne aspectos sociais, econômicos e culturais peculiares às ocupações ribeirinhas, como a agricultura familiar tradicional realizada sobre terra preta de índio (COSTA, 2010: 31). A agricultura é uma importante atividade econômica, seja através dos subprodutos da mandioca que são comercializados da Feira do Produtor Rural de Parintins, e também dos chamados quintais produtivos, caracterizados por uma elevada diversidade de espécies, majoritariamente frutíferas (idem: 53-54). Os moradores dessas localidades vivem ainda da pesca e caça, bem como de uma atividade pecuarista em crescimento. A produção de artesanato nos últimos anos tem-se intensificado entre os moradores, principalmente com intensa atividade turística desenvolvida no local.

A Comunidade Santa Rita de Cássia de Valeria situa-se no topo aplainado de uma península banhada pelo lago de Valéria, sobre um sítio arqueológico de grandes proporções. O sítio arqueológico que ali se situa foi inicialmente cadastrado como AM-PT-01 (SIMÕES e ARAÚJO-COSTA, 1978), e se caracteriza, em primeiro plano, pela matriz de solo formada pela Terra Preta de Índio - neossolo com alta densidade de material orgânico e outros elementos que a torna especialmente apropriada ao uso agrícola - resultante da ação humana no passado. Muito comuns na Amazônia, locais com este tipo de solo foram e são constantemente preferenciais para habitação e estabelecimento de roçados. Desta forma, as comunidades ribeirinhas estão, via de regra, assentadas sobre sítios arqueológicos.

Característica igualmente marcante do sítio arqueológico Santa Rita é sua elevada densidade de cerâmicas. Milhares de fragmentos, bem como muitos vasos inteiros, afloram na superfície da comunidade após cada chuva, seja nos quintais das casas, seja nas vias públicas. Assim sendo, a arqueologia está presente de maneira muito marcante no cotidiano dessas pessoas, que, à sua maneira, sempre deram significação a esses objetos. 


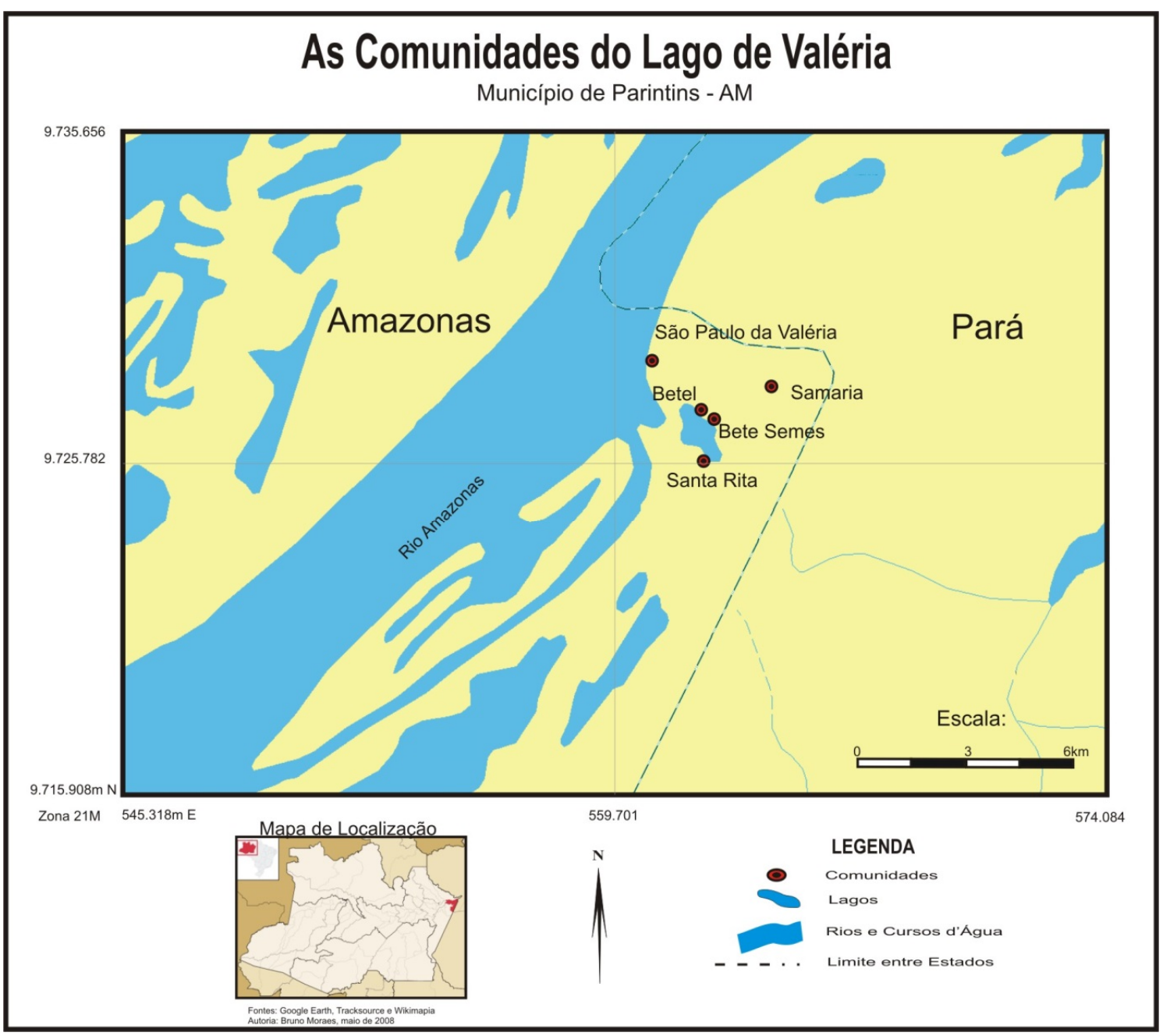

Fig.2: Mapa localizando as comunidades presentes no Lago da Valéria, município de Parintins/AM.

\subsection{O Turismo na Região da Valéria}

A chamada Serra de Parintins, onde se localiza o lago da Valéria, se situa na fronteira do estado do Pará e é circundada por uma densa vegetação rica em flora e fauna indicando o lugar como o portal turístico da localidade. Em razão de seu elevado potencial paisagístico natural e cultural, Valéria acabou por tornar-se alvo de intensa atividade turística extremamente predatória e desordenada.

Esse turismo tem dois públicos principais. Por um lado, a própria cidade de Parintins é referência no âmbito do turismo nacional e internacional. O famoso Festival do Boi de Parintins atrai milhares de pessoas para o município anualmente, que acabam por chegar às comunidades interioranas. No entanto, estes locais têm pouca ou nenhuma estrutura para atender tão intensa demanda. 
Por outro lado, a região de Valéria especificamente é um forte chamariz de outro tipo de turismo, igualmente predatório. Trata-se dos luxuosos cruzeiros internacionais que em acordo com instituições locais (como a Secretaria do Turismo) viajam regularmente pelo rio Amazonas para contemplar seus preciosos - e exóticos a estes olhos - encantos naturais e culturais. Em muitos casos, eles nem chegam à sede municipal, atendo-se a uma rápida observação dos modos de vida do caboclo amazônico e seu ambiente.

A intrínseca relação que as comunidades de Valéria desenvolveram com o turismo internacional é expressa, por exemplo, pela iniciativa local de criação de espaços para difundir a cultura e os costumes locais, onde encontram-se locais de venda de artesanato e onde são expostas algumas das peças arqueológicas. Portanto, além do artesanato local, geralmente feito com madeiras, sementes, penas e outros produtos da floresta, estes turistas também acabam entrando em contato com as peças arqueológicas. A esse respeito não são raros os relatos de que turistas os levem como "lembrança de Valéria" ou que os comprem de comunitários. Segundo relatos de alguns comunitários, essa comercialização de peças ocorreu pelo menos durante os últimos 35 anos.

Ainda, segundo os mesmos relatos, a primeira vez em que um navio de turistas estrangeiros aportou em Valéria foi em 1971. A maioria dessas embarcações, presença frequente na comunidade hoje, é composta de turistas vindos de todo o mundo, especialmente da Europa e Estados Unidos. Sendo essa região apenas mais um ponto dentro de um itinerário por vezes extenso, a parada é esperada pela maior parte dos viajantes como uma oportunidade de observação da natureza, principalmente espécimes de pássaros - bird watching. Munidos de câmeras com grandes lentes teleobjetivas, eles saem de seu enorme navio em pequenos barcos de transporte, dirigindo-se à comunidade de São Paulo da Valéria, que fica justamente na conjunção do rio Amazonas com o lago de Valéria, sendo por isso carinhosamente apelidada de "a boca da Valéria".

São Paulo da Valéria, comunidade pequena e que fica dispersa em uma estreita área entre o aclive de uma grande elevação montanhosa e o lago de Valéria, recebe então centenas de turistas, e se organiza devidamente para tanto. A recepção dos turistas torna-se um evento importante também para outras comunidades do entorno, que levam seus artesanatos para serem vendidos aos visitantes. Os turistas, por sua vez, saem das embarcações para adentrar a mata em suas observações, tendo a população local como guia, e também para conhecer o modo de vida daqueles que os recebem.

É, portanto, dessa interação - na qual a diferença linguística se constitui como principal barreira para a comunicação - entre os turistas e os moradores locais que ocorrem 
situações de "tráfico" de peças arqueológicas. É importante salientar que, na maioria dos casos, a iniciativa da venda parte dos moradores, e não da má-intenção dos visitantes. Este comércio é, na maior parte das vezes, empreendido pelos mais jovens, que desejam arrebanhar alguns dos dólares deixados navio após navio por esses esporádicos turistas.

Existiram, de fato, excursões à Valéria e outras regiões da Amazônia feitas com o objetivo claro de comercialização de artefatos arqueológicos, o que nunca foi encarado pelos habitantes de lá como um problema. Entretanto, este tipo de comércio era feito a partir de um número reduzido de pessoas, cujo perfil em muito se difere daqueles turistas que aportam na região em transatlânticos. O ponto a que gostaríamos de chegar é que o que diferencia o comércio esporádico voltado aos turistas e a venda feita a mercadores de peças arqueológicas - estes sim os verdadeiros traficantes - é a intencionalidade investida nas duas práticas e o modo como os agentes da transação se colocam frente à legislação vigente e frente ao patrimônio cultural em questão. É válido pontuar que estas duas formas de evasão de materiais arqueológicos dos sítios da região apresentam distinções bastante pronunciadas quanto ao tipo e quantidade de vestígio comercializado. No caso da venda de "souvenirs" para turistas, as peças vendidas são geralmente de pequenas dimensões, e o volume de material vendido é pouco significativo. Já os negociadores de peças possuem interesse em vasos inteiros, com decoração esteticamente relevante e, de forma geral, um grande número de peças é comercializado. Obviamente, embora a diferença de volume de material arqueológico comerciado em cada um desses eventos seja bastante pronunciada, sua frequência é bastante díspar. Um deles é bastante raro enquanto o outro acontece amiudadamente e de forma constante: todos os anos, ininterruptamente, aportam navios abarrotados de turistas que, eventualmente, poderão comprar e levar consigo estas peças, o que acaba tornando esta prática mais destrutiva do que aquela perpetrada por negociantes de peças.

Tal quadro de evasão das peças impunha a necessidade de ações sistemáticas diretas junto às comunidades ribeirinhas situadas nos sítios arqueológicos e em sua área de entorno, especialmente onde tais atividades ocorriam com maior intensidade. Este era o caso do município de Parintins, com seu reconhecido potencial arqueológico, representado pelos levantamentos e estudos anteriores (SIMÕES e ARAÚJO-COSTA, 1978; HILBERT e HILBERT, 1980).

Sugeriu-se, naquela ocasião, uma ação efetiva de Educação Patrimonial, o que víamos como alternativa para lidar com o êxodo das peças. Assim, a etapa subsequente do projeto, realizada em 2007, voltou-se para um projeto integrado de pesquisa participativa e educação patrimonial. Como pesquisa participativa, entende-se como a interação entre 
pesquisador e os grupos envolvidos na pesquisa, fazendo-se necessária uma metodologia que favoreça a discussão e integração do conhecimento acadêmico e tradicional. Dessa forma, partiu-se de uma postura não impositiva aos interesses da comunidade, para uma atitude de diálogo e negociação. Este método visa uma forma de desenvolvimento da pesquisa vinculada à abertura da pesquisa à participação da população local em todas as etapas do trabalho: localização de sítios, produção de cartas topográficas, escavação, etc, estimulando assim o olhar comunitário sobre o patrimônio coletivo, sua cultura material, imaterial e meio ambiente para uma perspectiva científica.

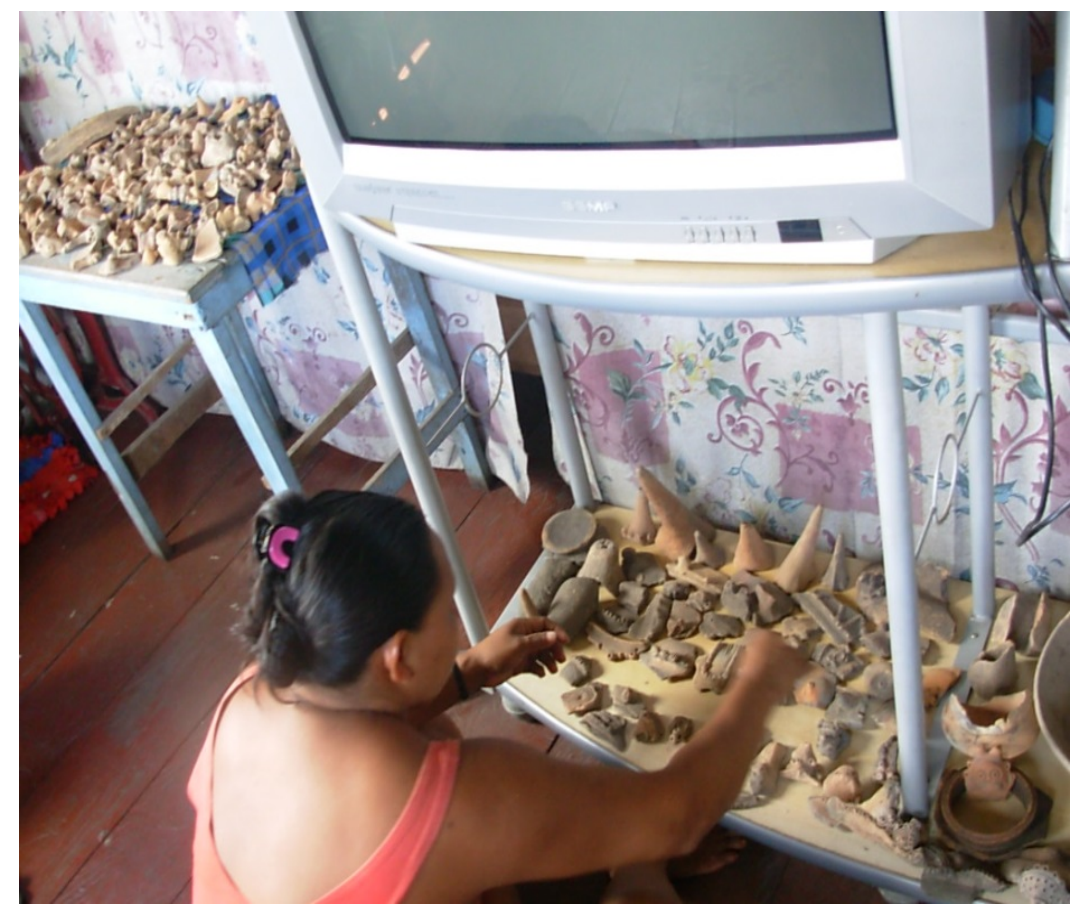

Fig.3: Coleção arqueológica presente em casa de moradora da Comunidade Santa Rita de Cássia (Valéria, Parintins/AM) (foto: Mauricio de Paiva, 2007).

\section{Delineamento Metodológico: a Pesquisa Participativa}

Convencionou-se chamar as bases do trabalho desenvolvido em Parintins como Pesquisa Participativa, ou seja, uma forma de desenvolvimento da pesquisa vinculada à ação ativa da população que se insere no local a ser estudado através da participação destes em todas as etapas do trabalho: localização de sítios, produção de cartas topográficas, escavação, etc. Este método visa estimular o olhar comunitário sobre o patrimônio coletivo, sua cultura material, imaterial e seu ambiente para uma gestão compartilhada do patrimônio arqueológico. A ponderação do conhecimento tradicional sobre o conhecimento arqueológico gerado a partir da pesquisa participativa implica em um íntimo diálogo entre o discurso científico e o 
discurso comunitário na leitura e interpretação do fenômeno arqueológico circunscrito na história e cotidiano dessas populações.

A inserção das comunidades no trabalho arqueológico em si foi também um dos resultados positivos da estratégia utilizada. A presença dos comunitários nas etapas de mapeamento topográfico, delimitação e escavações do sítio arqueológico mudou a visão interna sobre o trabalho, conferindo uma maior agilidade e trazendo um resultado mais positivo do que esperávamos. Ficou clara uma demanda pela continuação deste trabalho, dando uma perspectiva de longo prazo às pesquisas ali desenvolvidas.

\subsection{Ações do Projeto}

As atividades do projeto visaram não apenas mostrar aos moradores das comunidades de Valéria a importância histórica e cultural daquele patrimônio, mas também despertar questões, ligando os objetos à história do lugar e, consequentemente, com seu modus vivendi. O trabalho de Educação Patrimonial foi pensado como uma forma de levar às populações locais as questões arqueológicas sob as quais nos debruçamos, inserindo-as em seu cotidiano de modo que um novo olhar sobre os objetos os guiassem para a preservação de uma forma não-impositiva e espontânea.

Com efeito, a pesquisa participativa levada a cabo em Santa Rita rendeu frutos. Durante e após a estadia da equipe na comunidade, foram visíveis algumas mudanças na perspectiva da população em relação ao material arqueológico com o qual mantém contato cotidianamente e, também, com a historicidade do próprio lugar onde vivem. Neste sentido, houve um processo de reflexão acerca da ideia de patrimônio, antes ausente, e a necessidade de sua preservação e apropriação de forma consciente. Assim, aqueles que comercializavam as peças passaram a se ver como guardiões das coleções por eles reunidas.

Inicialmente, a chegada de "estranhos" (nós, os arqueólogos) na comunidade gerou certo distanciamento ou descaso por parte dos moradores. Eram comuns relatos de pesquisadores que passavam pela região, realizavam suas pesquisas sem ao menos fazer uma prévia comunicação ao presidente e à comunidade. Estes, tampouco, forneciam explicações sobre os trabalhos efetuados ou seus resultados. A frequência desta prática acabou por criar grande "descrença" nas pessoas quanto a projetos científicos. Menos ainda se acreditava que estes poderiam ser benéficos à comunidade e trazer retornos concretos aos moradores. Cientes de tal perspectiva e imbuídos pelo desejo de contribuir para uma mudança acerca destes elementos, realizamos, logo no primeiro dia, uma reunião com moradores da comunidade 
Santa Rita, a fim de elucidar os objetivos da pesquisa e de nossa estadia. No entanto, poucas pessoas compareceram, e com interesse diminuto.

Este quadro foi se modificando lentamente ao passo em que a pesquisa se desenvolvia. Arqueólogos observavam e eram observados o tempo todo. A curiosidade estimulada pelas ações de educação patrimonial, sempre dentro da comunidade, dentro das casas, dentro da escola, aliada à nossa estadia prolongada, de fato morando na comunidade, possibilitaram um processo de conhecimento mútuo. O aprendizado se deu sempre em duas vias em que, por um lado, nós vivenciávamos o cotidiano, dia e noite, da vida na comunidade e, por outro lado, trazíamos à tona discussões sobre a riqueza do patrimônio histórico e cultural daquele local, e a importância de sua preservação. Foram compartilhadas ideias como o que é e como se faz arqueologia, quais são seus objetos e suas finalidades, em conversas formais e informais.

Tudo isso foi gerando um crescente aumento de interesse pela arqueologia e pelas atividades que desenvolvíamos ali. A inserção das comunidades no trabalho arqueológico em si foi também um dos resultados positivos da estratégia utilizada. A presença dos comunitários nas etapas de mapeamento topográfico, delimitação e escavações do sítio arqueológico mudou a visão interna sobre o trabalho, conferindo maior agilidade e trazendo um resultado mais positivo do que esperávamos. Ficou claro uma demanda pela continuação deste trabalho, dando uma perspectiva de longo prazo às pesquisas que ali foram desenvolvidas. Ao final, os membros da equipe éramos nós e mais dezenas de pessoas que trabalharam ativamente nas mais diferenciadas tarefas concernentes ao trabalho de campo.

Foram realizadas novas etapas de campo entre os anos de 2007 e 2008, quando outras ações foram executadas. Uma delas foi a participação de alguns membros da equipe na tradicional feira de ciências promovida anualmente nas escolas da região. O grupo vencedor da feira de ciências, composto por seis alunos do ensino médio, fez uma apresentação sobre o patrimônio arqueológico local. Como premiação, os membros do grupo foram convidados para uma viagem a Manaus, a conhecerem e participarem de atividades no laboratório de arqueologia. Neste sentido, vimos que era importante que membros da própria comunidade participassem dos desdobramentos da pesquisa arqueológica, pois, findadas as atividades de campo, eles mesmos, criariam canais de comunicação acerca de impressões e aprendizados para o restante da comunidade. Assim, ainda em 2007 foi oferecido um curso a esses estudantes, acompanhados por uma professora e pela gestora da Escola Municipal Marcelino Henrique. O mesmo se deu no anexo laboratorial do Museu de Arqueologia e Etnologia da Universidade de São Paulo (MAE/USP), localizado em Manaus, onde foram executados os 
primeiros passos dos processos curatoriais dos vestígios coletados na comunidade, e algumas análises cerâmicas com o foco nos mesmos materiais.

Outra ação considerada de extrema importância, e que também surtiu interessantes resultados foi a realização de uma oficina de produção cerâmica artesanal, com inspiração arqueológica, aos moradores da comunidade. Além de se configurar como mais uma possibilidade de atividade econômica de produção de artesanato regional, o aprendizado deste ofício pode significar a chave para o fim da saída das peças arqueológicas, já que estas pessoas podem, elas próprias, produzirem réplicas daquele material encontrado sob a comunidade. Mais do que isso, uma oficina de (re)produção de cerâmica, aliada a um sólido trabalho de Educação Patrimonial, pode suscitar questões importantíssimas sobre aqueles que ali viveram antes deles, vinculando a sua história com a do lugar onde vivem.

\section{Resultados e discussões}

Ao analisar a situação mais de perto, acabamos por concluir que a forma como tal comércio de artefatos arqueológicos se dava não se enquadrava na definição corrente de tráfico, qual seja, "comércio ilegal e clandestino; contrabando"7 . Pelo contrário, o que víamos era um total desconhecimento tanto legal quanto da própria ideia de patrimônio por parte dos supostos "traficantes". As peças arqueológicas eram oferecidas mais por seu valor estético do que por seu valor arqueológico.

Por exemplo, através de muitas conversas, percebeu-se que estes objetos não estavam vinculados a um passado - humano ou paisagístico - da comunidade. Antes, eles são entendidos enquanto um dado da "natureza", assim como a terra, o lago, os peixes. Nenhuma atribuição histórica é (ou era) a eles remetida. Num contexto como este, a ideia de patrimônio não parece encontrar correspondência nas "caretinhas" cerâmicas ou nas terras pretas.

Portanto, se o tráfico se caracteriza por ser uma atividade de venda em que há a consciência da ilegalidade da negociação, então a situação em Santa Rita não pode ser enquadrada como tal. Além disso, acreditamos que muitos dos casos de tráfico de material arqueológico no interior da Amazônia funcionem da mesma forma, ou seja, uma das partes desconhece qualquer valor atribuído àqueles objetos que não o estético, e só o negociam devido a este desconhecimento. Encarar tal prática como ilegal para que se aplicassem as medidas cabíveis seria, no mínimo, um erro. Além de não se resolver o problema, criar-se-ia

\footnotetext{
${ }^{7}$ Definição extraída dos dicionários da língua portuguesa Aurélio e Delta Larrousse.
} 
outro grave problema social a se sobrepor ao primeiro. Então, ao contrário, tentamos compreender as peculiaridades desta interação, o que nos fez perceber que uma postura não impositiva e de diálogo poderia fazer toda a diferença, ao semear a ideia do valor histórico e cultural que aqueles objetos possuíam.

Além disso, a situação de êxodo de peças arqueológicas, conforme anteriormente mencionado, pode ser atribuído não exatamente ao desconhecimento dos preceitos arqueológicos que dizem respeito a uma história local contada através dos objetos, mas sim à própria interpretação da população local sobre o material arqueológico - plenamente inserido em sua vivência cotidiana. A forma pela qual esta situação vinha sendo encarada até então, enquanto um tráfico de fato (uma transação ilegal de cunho econômico), acabou por motivar toda uma série de ações que, apesar da impressão legalista inicial, permitiram que práticas antigas fossem repensadas pela comunidade, que decidiu de forma autônoma abandonar tais práticas. O que se seguiu foi que as peças foram acrescidas de novos significados e passaram a ser valorizadas de outro modo nas comunidades, chegando a aparecer em crescentes coleções organizadas pelos comunitários.

Um segundo fator de transformação do registro arqueológico no local é a própria situação do sítio arqueológico, que se encontra numa área habitada sofrendo constantes alterações pelas edificações e pelas atividades cotidianas dos moradores. Tal situação não é preocupante, a nosso ver. Em verdade, a ocupação atual interfere no registro arqueológico da mesma forma como outras ocupações que a precederam o fizeram, em uma continuação inegável da construção deste registro. Assim sendo, não é possível encará-lo enquanto um corpo imutável.

Em certo sentido, uma das finalidades da pesquisa arqueológica na Amazônia é o reconhecimento da diversidade cultural do passado. Encarada enquanto estudo do presente, a arqueologia pode demonstrar preocupação não somente com a preservação do patrimônio arqueológico, testemunho de uma história ainda parcamente conhecida, mas também com a própria sócio-diversidade manifestada na atualidade. Ao trazer à tona os resultados das pesquisas arqueológicas, abrem-se precedentes para repensar os modos de construção dessa história, bem como para pensar nas contribuições estratégicas que os povos do passado deixaram e que, por uma série de questões, estamos esquecendo. É importante ressaltar que os sítios arqueológicos - ainda que um legado do passado - constituem parte do presente.

Grande parte das comunidades ribeirinhas nesta área da Amazônia ocupa antigas áreas indígenas, de modo que estas populações mantêm um contato direto com os vestígios materiais produzidos por aqueles que os antecederam naquele local. Mais do que isso, estas 
pessoas possuem uma visão própria sobre estes vestígios, reinterpretando-os à luz de seus próprios conceitos e de relações com outros grupos. Não obstante, a visão de mundo impingida por estes moradores aos objetos arqueológicos não necessariamente passa pelas interpretações científicas já consolidadas, não raro colocando-as como representações divergentes, revestindo as ações dos cientistas de um caráter decerto mais "verdadeiro" do que aqueles externados pelas populações locais.

O projeto almejou, fundamentalmente, a partir da participação dos comunitários, uma construção do conhecimento arqueológico que levasse em consideração não apenas os critérios científicos, mas também as contribuições do conhecimento local sobre o contexto sistêmico aos quais aqueles materiais, sempre (re)significados, estão inseridos. Para tanto, entendemos como necessária, senão essencial, a inserção dos moradores em todos os passos do trabalho, olhando aqueles "cacos de pote" ou "caretinhas" e se consolidando como agentes históricos.

Neste sentido, ao contar com o envolvimento da comunidade ao longo de todas as suas etapas, intenciona-se não somente realizar uma coleta de dados arqueológicos e estabelecer pretensos vínculos culturais entre as populações pretéritas e presentes, mas também fazer com que o conhecimento produzido sirva às pessoas que efetivamente contribuem para que ele exista, agregando à pesquisa diferentes vozes envolvidas no processo de construção do conhecimento.
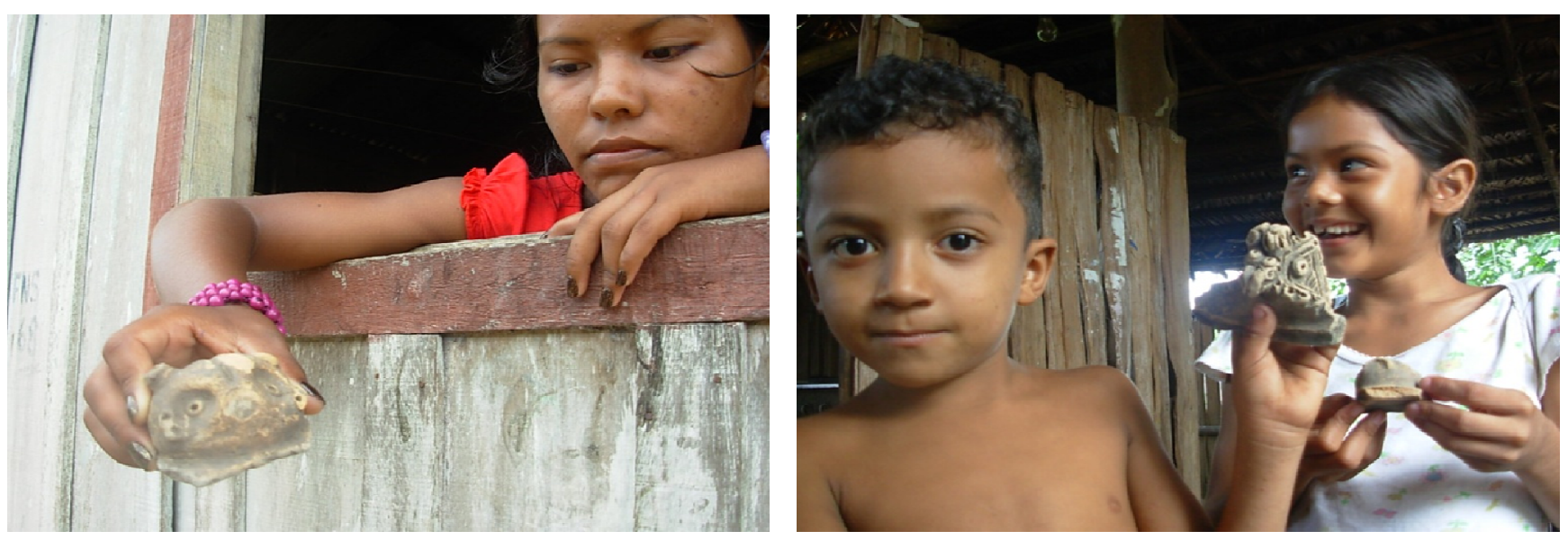

Fig.4 e 5: Crianças da Comunidade Santa Rita de Cássia (Valéria, Parintins/AM) mostram suas coleções e artefatos (Fotos: Maurício de Paiva, 2007).

\section{Referências bibliográficas}

BRUNO, Maria Cristina. "Arqueologia e Antropofagia: a musealização de sítios arqueológicos”. In: CHAGAS, M. Revista do Patrimônio - Museus. Brasília: IPHA, 2005. 
. Museologia: a Luta pela Perseguição ao Abandono. Tese de Livre-Docência defendida no Museu de Arqueologia e Etnologia da Universidade de São Paulo, 2001.

CARNEIRO, Carla Gibertnoni. Ações educacionais no contexto da arqueologia preventiva: uma proposta para a Amazônia. Tese de doutorado em arqueologia defendida no Museu de Arqueologia e Etnologia da Universidade de São Paulo, 2008.

CARNEIRO DA CUNHA, Manuela. Introdução. In: CARNEIRO DA CUNHA, Manuela (org.) Revista do Patrimônio - patrimônio imaterial e biodiversidade. Brasília: Instituto do Patrimônio Histórico e Artístico Nacional, 2005.

COSTA, Neymar. Construção do Conhecimento Agroecológico e Gestão Patrimonial no Sítio Arqueológico de Santa Rita de Cássia, Parintins/AM. Trabalho de Conclusão de Curso (TCC), Parintins: Curso de Tecnologia em Agroecologia, Centro de Estudos do Trópico Úmido, Universidade do Estado do Amazonas, 2011.

HILBERT, Peter; HILBERT, Klaus. "Resultados preliminares de pesquisa arqueológica nos rios Nhamundá e Trombetas, baixo Amazonas". In: Boletim do Museu Paraense Emilio Goeldi 75:1-11, 1980.

HORTA, Maria de Lourdes Parreiras; GRUNBERG, Evelina; MONTEIRO, Adriane Queiroz. Guia Básico de Educação Patrimonial. Brasília: Instituto do Patrimônio Histórico e Artístico Nacional, Museu Imperial, 1999.

LIMA, Helena. Projeto Baixo Amazonas: Serviços Técnicos de mapeamento arqueológico e Educação Patrimonial em áreas pré-selecionadas do município de Parintins, Estado do

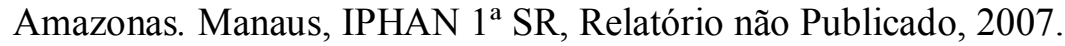

LIMA, Helena; SILVA, Carlos. Levantamento Arqueológico do Médio Amazonas. Manaus, IPHAN $1{ }^{\text {a }}$ SR, Relatório não Publicado, 2005.

LIMA, Helena; MORAES, Bruno; PARENTE, Maria T. Projeto Baixo Amazonas, Serviços Técnicos de Educação Patrimonial e Oficinas de Cerâmica. Relatório não publicado. IPHAN/AM, 2008.

LIMA, Tânia Andrade. Apresentação. In: LIMA, Tânia Andrade. Revista do Patrimônio Patrimônio Arqueológico: o desafio da preservação. Brasília: Instituto do Patrimônio Histórico e Artístico Nacional; 2007.

SANT’ANNA NÉRI, Frederico José de Santana. O país das Amazonas. Belo Horizonte, Editora da Universidade de São Paulo - Itatiaia, 1979.

SCHAAN, Denise P. "Múltiplas vozes, memórias e histórias" In: LIMA, T.A. Revista do Patrimônio - Patrimônio Arqueológico: o desafio da preservação Brasília: IPHAN, 2007.

SIMÕES, Mario. “Índice das fases arqueológicas brasileiras 1950 - 1971”. In: Publicações avulsas do Museu Paraense Emílio Goeldi, nº 18. Belém-PA, 1972.

. "Pesquisa e Cadastro de sítios arqueológicos na Amazônia Legal Brasileira". In:

Publicações Avulsas do Museu Paraense Emílio Goeldi nº 38, Belém-Pará, 1983. 
SIMÕES, Mario; ARAÚJO-COSTA, Fernanda. “Áreas da Amazônia Legal Brasileira para pesquisa e cadastro de sítios arqueológicos". In: Publicações Avulsas do Museu Paraense Emílio Goeldi no 30, Belém-Pará, 1978.

UGARTE, Auxiliomar. Sertões de Bárbaros: O mundo natural e as sociedades indígenas da Amazônia na visão dos cronistas ibéricos (séculos XVI-XVII). Manaus: Ed. Valer, 2010. 